
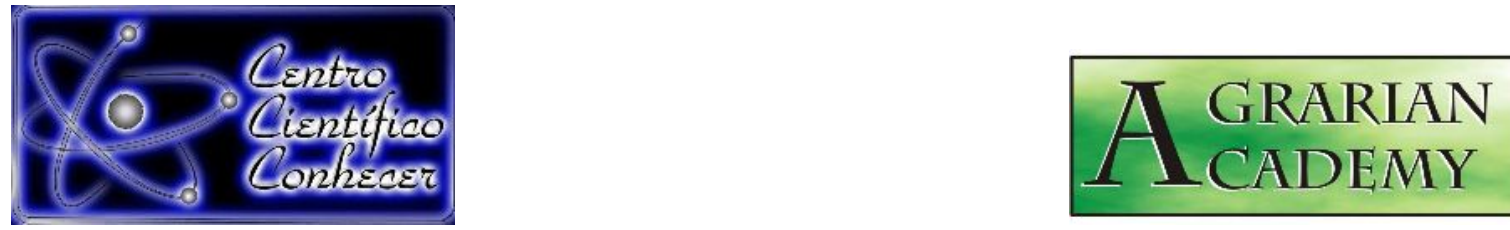

\title{
DESENVOLVIMENTO DE SORGO FORRAGEIRO SUBMETIDO À APLICAÇÃO DE MANIPUEIRA
}

Leandro Ricardo Rodrigues de Lucena1* ${ }^{*}$ Josimar Bento Simplício², Maurício Luiz de Mello Vieira Leite ${ }^{3}$

${ }^{1 * P r o f e s s o r, ~ D o u t o r ~ e m ~ B i o m e t r i a ~ e ~ E s t a t i ́ s t i c a ~ A p l i c a d a, ~ D e p a r t a m e n t o ~ d e ~ Z o o t e c n i a, ~}$ Universidade Federal Rural de Pernambuco, Serra Talhada, PE, Brasil, email: leandroricardo_est@yahoo.com.br

2Professor, Doutor em Agronomia, Departamento de Agronomia, Universidade Federal Rural de Pernambuco, Serra Talhada, PE, Brasil

${ }^{3}$ Professor, Doutor em Zootecnia, Departamento de Agronomia, Universidade Federal Rural de Pernambuco, Serra Talhada, PE, Brasil

Recebido em: 02/06/2019 - Aprovado em: 15/06/2019 - Publicado em: 22/07/2019 DOI: 10.18677/Agrarian_Academy_2019a13

A cultura do sorgo tem demonstrado grande potencialidade para ser utilizada na alimentação dos animais, sobretudo nas regiões semiáridas, pois apresenta alto potencial de produção de fitomassa, tolerância à seca, alto valor energético, boa aceitabilidade, boa digestibilidade, grande reserva de água e fácil propagação. Assim, objetivou-se avaliar a resposta de dois genótipos de sorgo forrageiro submetidos a condições de déficit hídrico e adubação com diferentes doses de manipueira. O experimento foi realizado em blocos casualizados, esquema fatorial $2 \times 4$, os tratamentos consistiram de duas cultivares de sorgo forrageiro e quatro doses de manipueira $\left(0,0 ; 12,0 ; 24,0\right.$ e $\left.48 \mathrm{~m}^{3} \mathrm{ha}^{-1}\right)$, com quatro repetições, totalizando 32 unidades experimentais. As características avaliadas foram diâmetro do colmo, altura de planta, número de folhas vivas, número de folhas mortas, peso da massa verde e peso da massa seca. Observou-se que a dose de 168,34 mL/vaso maximizou a altura da planto do sorgo IPA 2502, enquanto que a dose de 104,76 $\mathrm{mL} /$ vaso maximizou a altura da cultivar BRS Ponta Negra, já as doses de 168,06 e $101,71 \mathrm{~mL} /$ vaso maximizaram o diâmetros de colmo das cultivares IPA 2502 e BRS Ponta Negra, respectivamente. Não houve influência das diferentes dosagens de manipueria para o número de folhas vivas e mortas, peso da massa verde e peso da massa seca das cultivares IPA 2502 e BRS Ponta Negra. A utilização de manipueira promoveu incrementos na produção de forragem nos dois genótipos de sorgo forrageiro.

PALAVRAS-CHAVE: Estresse hídrico, Forragem, Superfície de resposta

\section{DEVELOPMENT OF FORAGE SORGUM UNDER CASSAVA WASTEWATER APPLICATION}




\begin{abstract}
The sorghum crop has shown great potential to use in animal feeding, especially in semi-arid regions, because it presents high potential for phytomass production, drought tolerance, high energy value, good acceptability, good digestibility, large water reserve and easy propagation. Thus, the objective of this research was to evaluate the response of two genotypes of forage sorghum under water deficit and cassava wastewater application. The experiment was realized in randomized blocks, in $2 \times 4$ factorial design, the treatments consisted of two cultivars of forage sorghum and four level of cassava wastewater $\left(0.0,12.0,24.0\right.$ and $\left.48 \mathrm{~m}^{3} \mathrm{ha}^{-1}\right)$, with four replicates, totaling 32 experiments of units. The evaluated characteristics were stem diameter, plant height, number of live leaves, number of dead leaves, weight of green mass and weight of dry mass. Observed that the dose of $168.34 \mathrm{~mL} /$ vasel maximized plant height of sorghum IPA 2502, while the dose of $104.76 \mathrm{~mL} / \mathrm{vase}$ maximized plant height of the cultivar BRS Ponta Negra. Doses of 168.06 and $101.71 \mathrm{~mL} / \mathrm{vase}$ maximized stem diameters of the cultivars IPA 2502 and BRS Ponta Negra, respectively. There is no influence of the different dosages of cassava wastewater for number of live and dead leaves, weight of the green mass and weight of the dry mass of cultivars IPA 2502 and BRS Ponta Negra. Use of cassava wastewater promoted increases in forage yield in the two sorghum genotypes.
\end{abstract}

KEYWORDS: Forage, Response surface, Water stress

\title{
INTRODUÇÃO
}

As plantas forrageiras são consideradas um dos principais fatores para o desenvolvimento da pecuária em todo o mundo, pois atuam como a fonte de alimento para os rebanhos e consequentemente têm participação expressiva na produção de leite e de carne. Essas plantas apresentam alto potencial de produção de fitomassa, tolerância à seca, alto valor energético, boa aceitabilidade, boa digestibilidade, grande reserva de água e fácil propagação (ALMEIDA, 2012; GALVÃO JÚNIOR et al., 2014; LEITE et al., 2019).

As plantas forrageiras em sua maioria apresentam crescimento perene, resistente à seca, adaptada a uma ampla diversidade de solos e adaptada a regiões de clima quente, apresenta bom desenvolvimento em regiões onde a precipitação pluvial média anual é superior aos 500 mm (LEITE et al., 2017; LUCENA et al., 2018).

O Semiárido pernambucano é uma região que possui grande potencial pecuário, entretanto, apresenta baixa disponibilidade e qualidade das forragens ao longo do ano, em função da sazonalidade das chuvas e dos longos períodos de seca, com chuvas concentradas em determinadas épocas, geralmente de três a quatro meses ao ano (LUCENA et al., 2016). Segundo Pereira et al. (2018), a baixa capacidade de suporte forrageiro das caatingas, o manejo e aproveitamento inadequado das pastagens, além do reduzido uso de tecnologias de convivência com as secas ocasionam baixa produtividade dos rebanhos.

O déficit hídrico no semiárido Pernambucano é bastante comum, esse déficit provoca mudanças na anatomia, fisiologia e bioquímica das plantas (ARAÚJO et al., 2010), podendo afetar todos os seus estágios de desenvolvimento. As plantas forrageiras do semiárido Pernambucano com a influência do estresse hídrico acabam sofrendo com o estresse salino, visto que as águas das regiões do semiárido pernambucano apresentam elevadas concentrações de sais (SILVA et al., 2018). O acúmulo de sais no solo promove um ambiente desfavorável para o 
desenvolvimento das plantas, pois altera, de forma negativa, o crescimento das culturas reduzindo a produtividade das plantas forrageiras em áreas agrícolas (MUNNS; TESTER, 2008). O estresse salino também promove o fechamento estomático que induz a redução na assimilação de $\mathrm{CO}_{2}$ e consequentemente menor crescimento da planta e menor acúmulo de biomassa (SILVA et al., 2018).

A cultura do sorgo tem demonstrado grande potencialidade para ser utilizada como gramínea na alimentação dos animais, sobretudo nas regiões semiáridas do Nordeste, com condições edafoclimáticas peculiares e que não são propícias ao desenvolvimento de culturas muito exigentes em água. Neste contexto, estudos como a utilização excessiva de fertilizantes minerais em sistemas de produção agrícola podem causar sérios danos ao meio ambiente, além de contribuir para o desequilíbrio nas reservas naturais de elementos essenciais para as plantas (VILLELA JUNIOR et al., 2007).

Dentre os diversos resíduos agroindustriais que apresentam potencialidade de uso como fertilizante agrícola está a manipueira que é um dos resíduos gerados no processamento da mandioca (Manihot esculenta Crantz) para obtenção da farinha ou fécula. Esse resíduo consiste em um líquido amarelo claro com consistência leitosa, que contém açúcares, amidos, proteínas, linamarina, sais e outras substâncias. Pode ser utilizada com critérios como fertilizante natural para as culturas, minimizando os efeitos danosos que tem causado ao ambiente. A manipueira apresenta em sua composição química, diversos nutrientes essenciais para a planta, o que confere á mesma um grande potencial de seu uso como fertilizante, principalmente devido à sua concentração de nitrogênio, fósforo e especialmente, o potássio, nutrientes esses fundamentais e necessários à nutrição das plantas.

Todos esses aspectos supracitados (estresse hídrico e adubação com manipueira) nos solos do semiárido Pernambucano fazem necessário o estudo das características agronômicas e modelagem do sorgo. O conhecimento das curvas de crescimento de uma espécie fornece informações muito úteis no cultivo e manejo de populações naturais, e têm grande importância biológica, pois possibilitam a viabilidade do cultivo de uma espécie pela avaliação da taxa de crescimento. A curva, descrevendo uma sequência de medidas de determinada característica de alguma espécie em função do tempo, geralmente peso, altura, comprimento, espessura, largura, área ou diâmetro, é denominada de curva de crescimento (LUCENA et al., 2016).

O ajuste de curvas de crescimento é uma ferramenta importante para obter conhecimento do crescimento da planta e de seus estádios fenológicos (LEITE et al., 2017; LUCENA et al., 2016). As curvas de crescimento geram informações úteis como: manejo adequado da cultura, período de maior crescimento da planta, época mais adequada para adubação e controle de pragas (MANGUEIRA et al. 2016).

Nas últimas décadas o crescimento em plantas forrageiras vem sendo bastante estudado como relatado por Sousa et al. (2015) que avaliaram o crescimento inicial do sorgo utilizando diferentes substratos. Já Sousa et al. (2017) que estudaram o crescimento do sorgo em diferentes lâminas de irrigação, Sousa et al. (2018) avaliaram o crescimento do sorgo utilizando compostos orgânicos, Sá et al. (2018) avaliaram o crescimento de sorgo sacarino utilizando adubação fosfatada, enquanto Almeida et al. (2017) estudaram o crescimento de Pennisetum galucum.

Diante do exposto, objetivou verificar o comportamento das características agronômicas em dois genótipos de sorgo forrageiro em condições de estresse hídrico e adubação com manipueira. 


\section{MATERIAL E MÉTODOS}

A pesquisa foi realizada na Universidade Federal Rural de Pernambuco, Unidade Acadêmica de Serra Talhada (UFRPE/UAST), Serra Talhada, Pernambuco, Brasil (Altitude: 429 m, latitude: $7^{\circ}$ 56' 15" S e longitude: 38 18' 45" O) (Figura 1). Conforme a classificação de Köppen, o clima é do tipo BSwh', denominado Semiárido, quente e seco, chuvas de verão-outono com pluviosidade média anual de $632,2 \mathrm{~mm} / \mathrm{ano}$, temperaturas do ar médias de $26{ }^{\circ} \mathrm{C}$ e umidade relativa do ar média de $60 \%$ (SILVA et al., 2011).

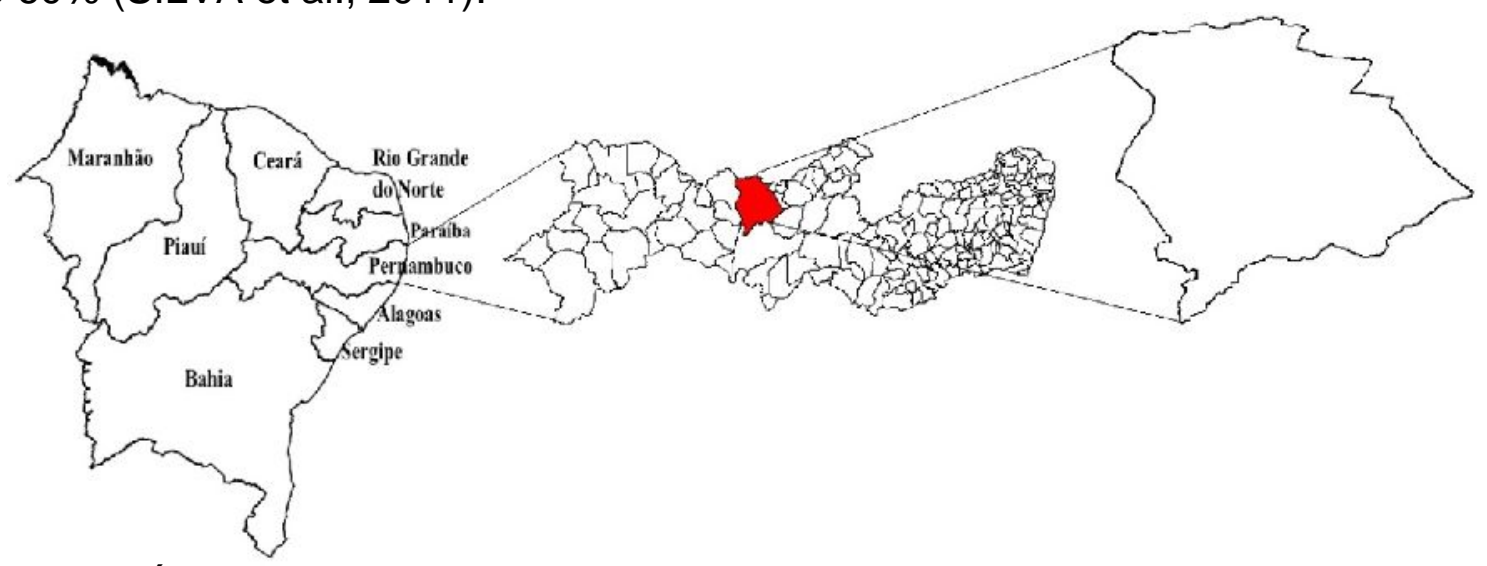

Figura 1. Área de estudo, município de Serra Talhada, estado de Pernambuco.

O solo utilizado no experimento (Typical Haplic Cambisol Ta Eutrophic) foi coletado a uma profundidade de $0-20 \mathrm{~cm}$, em seguida, homogeneizado e passado em peneira de $2,0 \mathrm{~mm}$. O solo após análise foi caracterizado pelos seguintes atributos químicos: $\mathrm{pH}$ (água) $=7,10 ; \mathrm{P}$ (extrator Mehlich I) $=40 \mathrm{mg} \mathrm{dm}^{-3} ; \mathrm{K}^{+}=0,33$; $\mathrm{Ca}^{2+}=2,70 ; \mathrm{Mg}^{2+}=1,20 ; \mathrm{Al}^{3+}=0,0 \mathrm{cmolc} \mathrm{dm}^{-3}$ (ALMEIDA et al., 2017).

$\mathrm{O}$ experimento foi instalado em blocos casualizados, em esquema fatorial $2 \times 4$, composto por duas cultivares de sorgo forrageiro e 4 doses de manipueira $(0,0$; 12,0; 24,0 e 48 m3.ha-1), correspondendo aos seguintes volumes: 0,0; 85,0; 170,0 e $340 \mathrm{~mL} / \mathrm{vaso}$, com quatro repetições, totalizando 32 unidades experimentais, representadas por vasos. Os vasos tiveram as seguintes dimensões: $29 \mathrm{~cm}$ (diâmetro) $\times 27 \mathrm{~cm}$ (altura), onde foram dispostos aleatoriamente sobre tijolos, colocando-se $25 \mathrm{Kg}$ de solo por vaso. Os atributos químicos da manipueira coletada estão listados na Tabela 1.

Tabela 1. Atributos químicos da manipueira

\begin{tabular}{lc}
\hline \multicolumn{1}{c}{ Atributos químicos } & Valores em $\mathrm{mg}^{-\mathrm{L}^{-1}}$ \\
\hline Potencial hidrogenionico $(\mathrm{pH})$ & 6,83 \\
Nitrogênio $(\mathrm{N})$ & 17,6 \\
Potássio $(\mathrm{K})$ & 4793,9 \\
Fosforo $(\mathrm{P})$ & 286,4 \\
Enxofre $(\mathrm{S})$ & 16,42 \\
Ouro $(\mathrm{Cu})$ & 0,39 \\
Zinco $(\mathrm{Zn})$ & 0,37 \\
Ferro $(\mathrm{Fe})$ & 47,20 \\
Magnésio $(\mathrm{Mg})$ & 1588,2 \\
Sódio $(\mathrm{Na})$ & 742,0 \\
Cálcio $(\mathrm{Ca})$ & 241,90 \\
\hline
\end{tabular}


Para a semeadura dos genótipos de sorgo, IPA 2502 e Ponta Negra foram colocadas três sementes por cova a cerca de 2,0 cm de profundidade. $O$ desbaste foi realizado dez dias após a emergência (DAE), procurando-se eliminar as plântulas menores e mais fracas, mantendo duas plântulas por vaso, onde foi avaliada a planta mais vigorosa de cada vaso. A irrigação foi realizada com a quantidade de 1 litro de água em cada vaso, a cada dois dias, simulando um estresse hídrico. Após o desbaste foram realizadas a cada sete dias aplicação da manipueira, durante todo o período experimental.

Foram realizadas análises biométricas de 10 em 10 dias, objetivando monitorar o crescimento e desenvolvimento da cultura, através das análises das variáveis: diâmetro do colmo (DC); altura de planta (AP); número de folhas vivas (NFV); número de folhas mortas (NFM); peso da massa verde (PMV) e peso da massa seca (PMS).

A altura das plantas (AP) foi determinada por meio de uma trena, medindo-se a distância vertical do solo até a extremidade da curvatura da última folha completamente expandida. $O$ diâmetro do colmo (DC) foi medido a $8 \mathrm{~cm}$ do nível do solo utilizando um paquímetro digital. Quanto ao número de folhas vivas (NFV) e mortas (NFM) foram contabilizadas apenas as folhas que apresentaram mais de $70 \%$ de coloração verde.

O peso da massa verde (PMV) e seca (PMS) foi calculado da seguinte forma: ao final do experimento, as plantas foram cortadas ao nível do solo, sendo em seguida ensacadas em sacos de papel e transportadas para o laboratório onde foram aferidos o peso da massa verde. Para determinação da massa seca foi colocada em estufa de circulação forçada de ar, com temperatura de $65^{\circ} \mathrm{C}$, até atingirem peso constante. Posteriormente o material foi pesado em balança de precisão para determinação da massa seca.

Foi utilizada análise de variância (ANOVA) para verificar a diferença do número de folhas vivas, número de folhas mortas, peso da massa verde e peso da massa seca com relação aos genótipos de sorgo e as diferentes dosagens de manipueira. Foi utilizada análise de superfície de resposta para encontrar os valores de dose de manipueira e idade de planta que maximizam o diâmetro do colmo e a altura das plantas para cada genótipo de sorgo nas condições de déficit hídrico.

A superfície de resposta é a representação geométrica obtida quando uma variável resposta é plotada como uma função de dois fatores quantitativos. A função pode ser assim definida pela Equação 1:

$$
\mathrm{Y}=\mathrm{f}\left(\mathrm{X}_{1}, \mathrm{X}_{2}\right)+\varepsilon
$$

em que:

$\mathrm{Y}$ - resposta (altura de planta e diâmetro e comprimento de colmo);

$\mathrm{X}_{1}$ e $\mathrm{X}_{2}$ - são os fatores (nível de manipueira e idade da planta);

$\varepsilon$ - erro aleatório.

No presente estudo a função $\mathrm{f}\left(\mathrm{x}_{1}, \mathrm{x}_{2}\right)$ é definida por:

$$
Y=f\left(X_{1}, X_{2}\right)+\varepsilon=\beta_{0}+\beta_{1} X_{1}+\beta_{2} X_{2}+\beta_{3} X_{1} X_{2}+\beta_{4} X_{1}^{2}+\beta_{5} X_{2}^{2}+\varepsilon
$$

em que, $\beta_{0}, \beta_{1}, \beta_{2}, \beta_{3}, \beta_{4}$ e $\beta_{5}$ são os parâmetros desconhecidos e estimados pelas equações 2.

AGRARIAN ACADEMY, Centro Científico Conhecer - Goiânia, v.6, n.11; p. 137 


$$
\widehat{\beta}=\left(X^{\prime} X\right)^{-1} X^{\prime} Y
$$

Para testar a significância do modelo ajustado é realizado um procedimento de análise de variância (ANOVA). Considerando o sistema de equações normais abaixo temos:

$$
X^{\prime} X \hat{\beta}=X^{\prime} Y
$$

Podemos obter as somas de quadrados total (SQT), tratamento (SQReg) e resíduos (SQR) pela ANOVA,

$$
S Q T=Y^{\prime} Y-C=\sum_{i=1}^{N} Y_{i}^{2}-C
$$

$$
\begin{aligned}
& \text { SQR }=Y^{\prime} Y-\hat{\beta}^{\prime} X^{\prime} Y \\
& \text { SQReg }=\hat{\beta}^{t} X^{t} Y-Y^{t} Y
\end{aligned}
$$

em que, $\mathrm{C}=\frac{\left(\sum_{i=2}^{\mathbb{N}} \mathrm{y}_{i}\right)^{2}}{\mathrm{~N}}$.

Para avaliar a adequação do modelo foi utilizado o coeficiente de determinação do modelo ajustado $R_{\mathrm{aju}}^{2}$, definido por:

$$
\mathrm{R}_{\mathrm{aju}}^{2}=\frac{\mathrm{R}^{2}(\mathrm{~N}-1)-\mathrm{p}}{\mathrm{N}-\mathrm{p}-1} ; \quad 0 \leq \mathrm{R}_{\mathrm{aju}}^{2} \leq 1 .
$$

em que, $R^{2}=\frac{\text { SQReg }}{\text { SQT }}$.

Foi adotado nível de $5 \%$ de significância para todas as análises. Os resultados foram gerados utilizando software R-project 2.13.1®.

\section{RESULTADOS}

$\mathrm{Na}$ avaliação da altura de planta (AP) verificou-se que o aumento das doses de manipueira promoveu efeito quadrático em ambos os genótipos de sorgo forrageiro com alto poder de precisão $R^{2}$ de $98,91 \%$ para o genótipo IPA 2502 e $\mathrm{R}^{2}$ de $96,42 \%$ para o genótipo BRS Ponta Negra (Figuras 2a e 2b). Para o genótipo IPA 2505 tem-se que o maior valor de altura de planta $(66,94 \mathrm{~cm})$ é dado com uma dosagem de manipueira de $168,34 \mathrm{~mL} / \mathrm{vaso}$ e idade da planta de aproximadamente 62,51 dias, já para o genótipo BRS Ponta Negra a máxima altura de planta $(85,25$ $\mathrm{cm}$ ) é definida por uma dosagem de 104,76 mL/vaso e idade de planta 68,65 dias. 


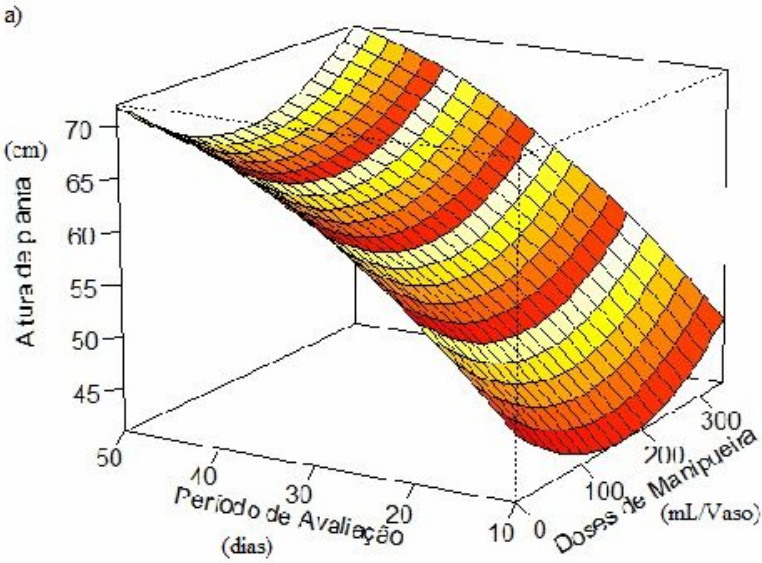

AP - 36,35-0,074Duse+1,178DAE+0,0002198Duse -0,009423DAE2 $\mathrm{R}^{2}-98,91 \%$

DAF= $=62.51$ Dose $=168,34$

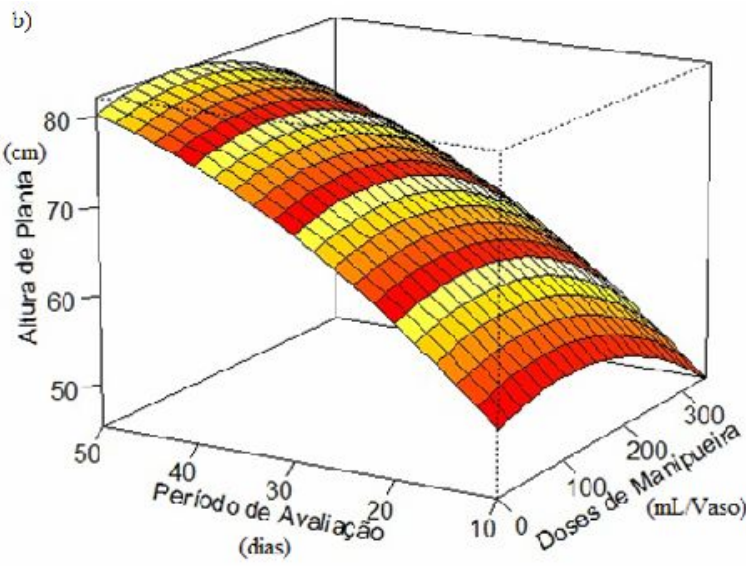

$\mathrm{AP}=41,4810,0352 \mathrm{Dose} 1,222 \mathrm{DAE}-0,000158 \mathrm{Dose}^{3}-0,008 \mathrm{SAE}^{\prime}$ $\mathrm{R}^{2}=96,42 \%$

$\mathrm{DAH}=68.65$ Jose $=104.76$

Figura 2. Altura de planta de sorgo forrageiro (a) IPA 2502 e (b) BRS Ponta Negra, em função das doses de manipueira e idade de planta.

Resultados similares aos desta pesquisa foram relatados por: Magalhães et al. (2014) onde verificaram alterações no crescimento do milho híbrido AG-1051 pelo uso de diferentes dosagens de manipueira. Dantas et. al. (2015) avaliando o comportamento do girassol Hélio 250, utilizando doses de $(0 ; 8,5 ; 17 ; 34 ; 68$ e 136 $\mathrm{m}^{3}$.ha ${ }^{-1}$ ) concluíram que a dose de $136 \mathrm{~m}^{3} \cdot \mathrm{ha}^{-1}$ de manipueira proporcionou um desenvolvimento mais adequado das plantas sendo a maior altura de planta obtida aos 60 dias após a semeadura, recomendado o uso da manipueira como fonte de nutrientes para a cultura do girassol.

Ressalta-se que o genótipo BRS Ponta Negra apresentou maior altura de planta nas mesmas condições que o IPA 2502, sendo o mesmo $62,23 \%$ mais eficiente quando submetido aos tratamentos com manipueira, precisando de menor dose de adubação com manipueira para alcançar maior altura de planta, concluindo que, doses superiores às apresentadas comprometeram o desenvolvimento das plantas.

Assim como a altura de planta verifica-se comportamento quadrático para o diâmetro do colmo (DC) em ambos os genótipos de sorgo nas condições de estresse hídrico com elevado poder de precisão $\left(R^{2}\right.$ de $96,33 \%$ e $97,83 \%$ para IPA 2502 e BRS Ponta Negra, respectivamente), Figuras 3a e 3b. A dosagem de 168,06 $\mathrm{mL} / \mathrm{vaso}$ de manipueira e uma idade de planta de aproximadamente 49 dias proporcionou o maior diâmetro de colmo $(11,82 \mathrm{~mm})$ para o genótipo IPA 2502, enquanto para o genótipo BRS Ponta Negra a dose de manipueira de 101,71 $\mathrm{mL} / \mathrm{vaso}$ e idade de planta de aproximadamente 64 dias maximizaram o diâmetro de colmo em 13,69 mm. 


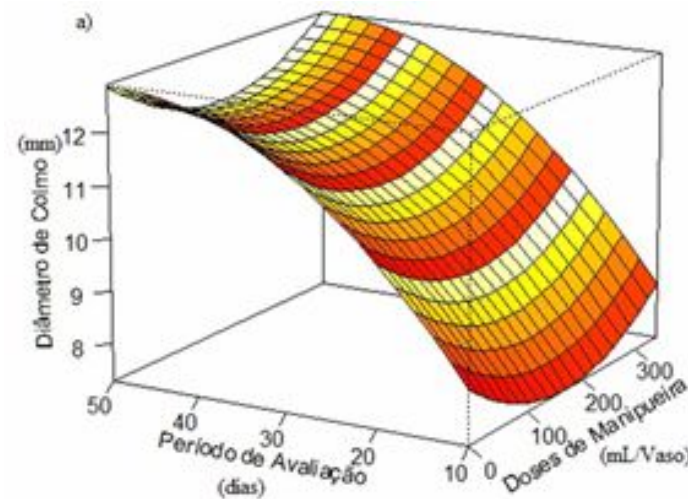

$\mathrm{DC}=5,715-0,0121 \mathrm{Dose}+0,2895 \mathrm{DAE}+0,000036 \mathrm{Dose}^{2}-0,00294 \mathrm{DAE}:$ $\mathrm{R}^{2}=96,33 \%$

$\mathrm{DAE}=49,23$ Dose $=168,06$

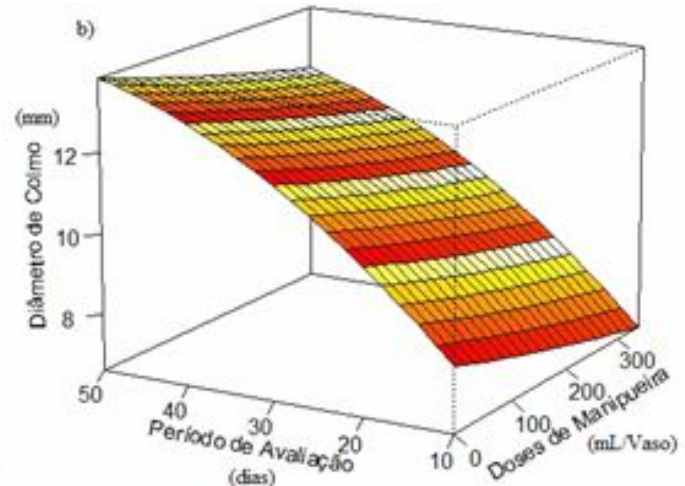

DC $=5,81-0,005696$ Dose $+0,2623 \mathrm{DAE}+0,0000028 \mathrm{Dose}^{2}-0,00204 \mathrm{DAE}$ $\mathrm{R}^{2}=97,83 \%$

DAE $=64,29$ Dose $=101,71$

Figura 3. Diâmetro de colmo (DC) (a) IPA 2502; (b) BRS Ponta Negra, em função das doses de manipueira.

Magalhães et al. (2014) avaliando o comportamento de plantas do milho híbrido AG-1051, em função de doses de manipueira, em ambiente controlado verificaram que a dose equivalente a $63 \mathrm{~m}^{3} \cdot \mathrm{ha}^{-1}$ propiciou maior ganho de diâmetro de colmo, concluindo que, o uso da manipueira serviu como fonte de adubação para a cultura do milho cujas respostas dependeram da utilização de doses adequadas do resíduo.

Ressalta-se que o genótipo BRS Ponta Negra apresentou maior diâmetro de colmo nas mesmas condições que o IPA 2502, sendo o mesmo 60,50\% mais eficiente quando submetido aos tratamentos com manipueira, precisando de menor dose de adubação com manipueira para alcançar maior diâmetro de colmo.

Não houve influência das diferentes dosagens de manipueria para o número de folhas vivas e mortas, peso da massa verde e peso da massa seca das cultivares IPA 2502 e BRS Ponta Negra, aos 77 dias após a emergência (Tabela 2). Esses resultados estão relacionados à condição de déficit hídrico na qual as plantas foram submetidas, uma vez que, é importante que ocorra um equilíbrio entre a quantidade dos nutrientes no solo e o volume de água dentro do sistema.

Tabela 2. Número de folhas vivas (NFV), número de folhas mortas (NFM), peso da massa verde (PMV) e peso da massa seca (PMS) das cultivares IPA 2502 e BRS Ponta Negra em função das doses de manipueira

\begin{tabular}{ccc}
$\begin{array}{c}\text { Doses de manipueira } \\
\text { (mL/vaso) }\end{array}$ & \multicolumn{2}{c}{$\begin{array}{c}\text { Genótipos de Sorgo } \\
\text { (Média } \pm \text { DP) }\end{array}$} \\
\cline { 2 - 3 } & IPA 2502 & $\begin{array}{c}\text { BRS Ponta Negra } \\
\text { NFV }\end{array}$ \\
0 & $5,75 \pm 0,5 \mathrm{Aa}$ & $5,75 \pm 0,5 \mathrm{Aa}$ \\
85 & $5,50 \pm 0,6 \mathrm{Aa}$ & $6,00 \pm 0,5 \mathrm{Aa}$ \\
170 & $6,00 \pm 0,5 \mathrm{Aa}$ & $6,25 \pm 0,5 \mathrm{Aa}$ \\
340 & $6,25 \pm 0,5 \mathrm{Aa}$ & $5,75 \pm 0,5 \mathrm{Aa}$ \\
& & NFM \\
0 & $4,00 \pm 0,5 \mathrm{Aa}$ & $4,5 \pm 0,6 \mathrm{Aa}$ \\
85 & $4,25 \pm 0,5 \mathrm{Aa}$ & $4,5 \pm 0,6 \mathrm{Aa}$ \\
170 & $4,25 \pm 0,5 \mathrm{Aa}$ & $4,0 \pm 0,5 \mathrm{Aa}$ \\
340 & $4,25 \pm 0,5 \mathrm{Aa}$ & $4,25 \pm 0,5 \mathrm{Aa}$
\end{tabular}

AGRARIAN ACADEMY, Centro Científico Conhecer - Goiânia, v.6, n.11; p. 140 


\begin{tabular}{ccc} 
& \multicolumn{2}{c}{ PMV $(\mathrm{g})$} \\
0 & $52,62 \pm 24,0 \mathrm{Aa}$ & $57,11 \pm 26,94 \mathrm{Aa}$ \\
85 & $40,20 \pm 7,77 \mathrm{Aa}$ & $49,05 \pm 8,69 \mathrm{Aa}$ \\
170 & $44,71 \pm 17,47 \mathrm{Aa}$ & $48,92 \pm 11,12 \mathrm{Aa}$ \\
340 & $51,95 \pm 25,29 \mathrm{Aa}$ & $46,87 \pm 5,70 \mathrm{Aa}$ \\
\multicolumn{2}{c}{$\mathrm{PMS}(\mathrm{g})$} \\
0 & $17,47 \pm 9,36 \mathrm{Aa}$ & $17,49 \pm 9,16 \mathrm{Aa}$ \\
85 & $12,75 \pm 3,31 \mathrm{Aa}$ & $13,80 \pm 2,20 \mathrm{Aa}$ \\
170 & $14,23 \pm 6,36 \mathrm{Aa}$ & $14,24 \pm 2,97 \mathrm{Aa}$ \\
340 & $16,75 \pm 9,87 \mathrm{Aa}$ & $11,08 \pm 1,52 \mathrm{Aa}$
\end{tabular}

Médias seguidas por letras iguais, maiúsculas nas colunas e minúsculas nas linhas, não diferem estatisticamente de acordo com o teste de Tukey $(p<0,05)$. DP = Desvio padrão.

Silva et al. (2004) estudando o comportamento do sorgo submetido a doses: 150, 450 e $900 \mathrm{~m}^{3}$.ha ${ }^{-1}$ por ano de efluente maturado de fecularia de mandioca, observaram que as necessidades nutricionais exigidas foram supridas pelo sorgo para o seu pleno desenvolvimento e produção de massa verde (ou massa seca), com resposta positiva em crescimento até a dose máxima adicionada de $450 \mathrm{~m}^{3} \mathrm{ha}^{-1}$. Barreto et al. (2014) avaliaram que o conteúdo da massa verde das plantas de milho elevou devido o aumento das doses de manipueira utilizadas na fertilização do solo.

Magalhães et al. (2014) avaliando o comportamento de plantas do milho híbrido AG-1051, em função de doses de manipueira verificaram que a dose equivalente a $63 \mathrm{~m}^{3}$.ha- ${ }^{-1}$ propiciou maior ganho do número de folhas, massa verde e massa seca de folhas. Dantas et al. (2015) avaliando o comportamento do girassol Hélio 250, utilizando doses de manipueira equivalentes a: 0; 8,5; 17; 34; 68 e 136 $\mathrm{m}^{3}$.ha ${ }^{-1}$, concluíram que a dose de $136 \mathrm{~m}^{3}$.ha ${ }^{-1}$ de manipueira maximizou o número de folhas, massa verde e massa seca das folhas aos 60 dias após a semeadura, recomendado o uso da manipueira como fonte de nutrientes para a cultura do girassol.

Apesar de a literatura disponibilizar vários trabalhos com o uso da manipueira (SARAIVA et al., 2007; BARRETO et al., 2014; MAGALHÃES et al., 2014; DANTAS et al., 2015), ainda são inconclusivos os resultados quanto à dose certa do produto para atender as necessidades nutricionais das culturas. Ressaltando que a proposta desta pesquisa teve como premissa simular uma condição de estresse hídrico para os genótipos de sorgo, limitando o fornecimento de água para as plantas em um litro por vaso com turno de rega de 48 horas, durante os 77 dias da condução da pesquisa.

Assim, é possível destacar que, nas condições em que foi desenvolvida esta pesquisa os resultados alcançados merecem destaque, pois com menos de 50 litros de água para um vaso com capacidade para $25 \mathrm{~kg}$ de solo, as plantas de sorgo resistiram, conferindo-lhes rusticidade e tolerância aos estresses abióticos a que foram submetidos. Nesse sentido, a similaridade entre as cultivares de sorgo forrageiro constatada nesse experimento, pode-se atribuir a condição severa de déficit hídrico na qual as plantas foram submetidas.

\section{CONCLUSÃO}

A utilização de manipueira promoveu incrementos na produção de forragem nos dois genótipos de sorgo forrageiro, no entanto são necessárias avaliações posteriores com novos estudos sobre a influência da manipueira, uma vez que as plantas estavam condicionadas ao estresse hídrico. 
A cultivar IPA 2502 apresenta maior rendimento forrageiro e crescimento quando aplicado dose de $168 \mathrm{~mL}$ por vaso de manipueira, enquanto que a cultivar BRS Ponta Negra necessita de $105 \mathrm{~mL}$ por vaso de manipueira para alcançar seu máximo rendimento e crescimento.

\section{REFERÊNCIAS}

ALMEIDA, R. F. Palma forrageira na alimentação de ovinos e caprinos no semiárido brasileiro. Revista Verde de Agroecologia e Desenvolvimento Sustentável. v. 7, p. $\quad 08-14, \quad 2012 . \quad$ Disponível em https://www.gvaa.com.br/revista/index.php/RVADS/article/view/1113/1334

ALMEIDA, M. C. R.; LEITE, M. L. M. V.; SÁ JR., E. H.; CRUZ, M. G.; MOURA, G. A. et al. Crescimento vegetativo de cultivares de milheto sob diferentes disponibilidades hídricas. Magistra, v. 29, n. 2, p. 161-171, 2017. Disponível em: https://magistraonline.ufrb.edu.br/index.php/magistra/article/view/571/316

ARAÚJO, S. A. C.; VASQUEZ, H. M.; CAMPOSTRINI, E.; NETTO, A. T.; DEMINICIS, B. B. et al. Características fotossintéticas de genótipos de capimelefante anão (Pennisetum purpureum Schum.) em estresse hídrico. Acta Scientiarum: Animal Sciences, v. 32, n. 1, p. 1-7, 2010. DOI: 10.4025/actascianimsci.v32i1.8961

BARRETO, M. T. L.; MAGAlhÃES, A. G.; ROLIM, M. M.; PEDROSA, E. M. R.; DUARTE, A. S. et al. Desenvolvimento e acúmulo de macronutrientes em plantas de milho biofertilizadas com manipueira. Revista Brasileira de Engenharia Agrícola e Ambiental, v. 18, n. 5, p. 487-494, 2014. DOI: http://dx.doi.org/10.1590/S141543662014000500004.

DANTAS, M. S. M.; ROLIM, M. M.; DUARTE, A. S.; PEDROSA, E. M. R.; TABOSA, J. N. et al. Crescimento do girassol adubado com resíduo líquido do processamento de mandioca. Revista Brasileira de Engenharia Agrícola e Ambiental, v. 19, n. 4, p. 350-357, 2015. DOI: http://dx.doi.org/10.1590/1807-1929/agriambi.v19n4p350-357

GALVÃO JÚNIOR, J. G. B.; SILVA, J. B. A.; MORAIS, J. H. G.; LIMA, R. N. Palma forrageira na alimentação de ruminantes: cultivo e utilização. Acta Veterinaria Brasilica, v. 8, p. 78-85, 2014. DOI: https://doi.org/10.21708/avb.2014.8.2.3490

LEITE, M. L. M. V.; LUCENA, L. R. R.; SÁ JÚNIOR, E. H.; CRUZ, M. G. Estimativa da área foliar em Urochloa mosambicensis por dimensões lineares. Revista Agropecuária Técnica, v. 38, n.1, p. 9-16, $2017 . \quad$ DOI: https://doi.org/10.25066/agrotec.v38i1.32041

LEITE, M. L. M. V.; LUCENA, L. R. R.; CRUS, M. G.; SÁ JR., E. H.; SIMÕES, V. J. L. $P$. Leaf area estimate of Pennisetum glaucum by linear dimensions. Acta Scientiarum Animal Science, v. 41, p. e42808 2019. DOI: 10.4025/actascianimsci.v41i1.42808 
LUCENA, L. R. R.; LEITE, M. L. M. V.; PEREIRA, J. S.; CAVALCANTE, A. B. Ajuste de curvas de crescimento do comprimento do cladódio de Nopalea cochenillifera. Biomatemática, v. 26, p. 39-52, 2016. Disponível em: http://www.ime.unicamp.br/ biomat/Bio26_art4.pdf

LUCENA, L. R. R.; LEITE, M. L. M. V.; SIMÕES, V. J. L. P.; SIMÕES, V. J. L. P.; ALMEIDA, M. C. R. Área de cladódio da palma Opuntia stricta utilizando dimensões lineares. Agrarian Academy, v. 5, n. 9, p. 46-55, 2018. DOI: 0.18677/Agrarian_Academy_2018a5

MAGALHÃES, A. G.; ROLIM, M. M.; DUARTE, A. S.; NETO, E. B.; TABOSA, J. N. et al. Desenvolvimento inicial do milho submetido à adubação com manipueira. Revista Brasileira de Engenharia Agrícola e Ambiental, v. 18, n. 7, p. 675-681, 2014. DOI: http://dx.doi.org/10.1590/S1415-43662014000700001

MANGUEIRA, R. A. F.; SAVIAN, T. V.; MUNIZ, J. A.; SERMARINI, R. A.; CROSARIOL NETTO, J. O. Modelo logístico considerando diferentes distribuições para os erros aplicados a dados de altura do milho. Revista Brasileira de Biometria, v. 34, n. 2, p. 317-333, 2016. Disponível em: http://www.biometria.ufla.br/index.php/BBJ/article/view/143

MUNNS, R.; TESTER, M. Mechanisms of Salinity Tolerance. Annual Review of Plant Biology, v. 59, n. 1, p. 651-681, 2008. DOI: 10.1146/annurev.arplant.59.032607.092911

PEREIRA, J. S.; LEITE, M. L. M. V.; CAVALCANTE, A. B.; LUCENA, L. R. R. Crescimento inicial de Nopalea cochenillifera em função do fracionamento do cladódio. Revista Agropecuária Técnica, v. 39, n. 2, p. 120-128, 2018. DOI: https://doi.org/ 10.25066/agrotec.v39i2.37995

SÁ, F. V. S.; MESQUITA, E. F.; MELO, U. A.; PAIVA, E. P.; BERTINO, A. M. P. et al. Crescimento e biomassa em plantas de sorgo sacarino irrigados com água salina sob adubação fosfatada. Revista Brasileira de Agricultura Irrigada, v. 12, n. 2, p. 2561-2569, 2018. DOI: 10.7127/rbai.v12n200826

SARAIVA, F. Z.; SAMPAIO, S. C.; SILVESTRE, M. G.; QUEIROZ, M. M. F.; NÓBREGA, L. H. P. et al. Uso de manipueira no desenvolvimento vegetativo do milho em ambiente protegido. Revista Brasileira de Engenharia Agrícola e Ambiental, v. 11, n. 1, p. 30-36, 2007. DOI: http://dx.doi.org/10.1590/S141543662007000100004

SILVA, F. F.; FREITAS, P. S. L.; BERTONHA, A.; MUNIZ, A. S.; REZENDE, R. Impacto da aplicação de efluente maturado de fecularia de mandioca em solo e na cultura do sorgo. Acta Scientiarum Agronomy, v. 26, n. 4, p. 421-427, 2004. DOI: 10.4025/actasciagron.v26i4.1801

SILVA, A. O.; MOURA, G. B. A.; SILVA, E. F. F.; LOPES, P. M. O.; SILVA, A. P. N. Análise espaço-temporal da evapotranspiração de referência sob diferentes regimes de precipitação em Pernambuco. Revista Caatinga, v. 24, n. 2, p. 135-142, 2011. 
Disponível

em:

https://periodicos.ufersa.edu.br/index.php/caatinga/article/view/1889/4723

SILVA, J. R. I.; JARDIM, A. M. R. F.; NETO, J. B.; LEITE, M. L. M. V.; TEIXEIRA, V. I. Estresse salino como desafio para produção de plantas forrageiras. Pesquisa Aplicada \& Agrotecnologia, v. 11, n. 3, p. 127-139, 2018. DOI: 10.5935/PAeT.V11.N3.13

SOUSA, G. C.; RIBEIRO, A. A.; MENEZES, A. S.; MOREIRA, F. J. C.; CUNHA, C. S. M. Emergência e crescimento inicial de sorgo (Sorghum bicolor L.) em diferentes substratos. Agropecuária Científica no Semiárido, v. 11, n. 4, p. 63-71, 2015. DOI: 10.30969/acsa.v11i4.709

SOUSA, P. G. R.; VIANA, T. V. A.; CARVALHO, C. M.; SOUSA, A. M.; COSTA, C. P. $M$. et al. Efeito de diferentes lâminas de irrigação e cobertura do solo no crescimento da cultura do sorgo. Revista Brasileira de Agricultura Irrigada, v. 11, n. 4, p. 15281537, 2017. DOI: $10.7127 /$ rbai.v11n400592

SOUSA, R. A.; LACERDA, C. F.; NEVES, A. L. R.; COSTA, R. N. T.; HERNANDEZ, F. F. F. et al. Crescimento do sorgo em função da irrigação com água salobra e aplicação de compostos orgânicos. Revista Brasileira de Agricultura Irrigada, v. 12, n. 1, p. 2315-2326, 2018. DOI: 10.7127/rbai.v12n100696

VILLELA JÚNIOR, L. V. E.; ARAÚJO, J. A. C.; BARBOSA, J. C.; PEREZ, L. R. B. Substrato e solução nutritiva, desenvolvidos a partir de efluente de biodigestor para cultivo do meloeiro. Revista Brasileira de Engenharia Agrícola e Ambiental, v. 11, n. 2, p. 152-158, 2007. DOI: http://dx.doi.org/10.1590/S1415-43662007000200004 